\title{
Estimating Differences in Risk of Chronic Kidney Disease Based on Water Intake in a National Sample
}

\author{
David Lartey $^{a} \quad$ Mark Greenwood $^{a}$ b Greta Linse $^{b} \quad$ Sally Moyce ${ }^{c}$ Cynthia Curl ${ }^{d}$ \\ Meredith Spivak $^{d}$ Evan C. Johnson ${ }^{\mathrm{e}}$ \\ ${ }^{a}$ Department of Mathematical Science, Montana State University, Bozeman, MT, USA; ${ }^{b}$ Department of Mathematical \\ Sciences, Statistical Consulting and Research Services, Montana State University, Bozeman, MT, USA; 'College of \\ Nursing, Montana State University, Bozeman, MT, USA; ${ }^{\mathrm{d} C e n t e r}$ for Excellence in Environmental Health and Safety, \\ Boise State University, Boise, ID, USA; 'Division of Kinesiology \& Health, University of Wyoming, Laramie, WY, USA
}

\section{Keywords \\ Kidney disease $\cdot$ National health and nutrition examination survey $\cdot$ Hydration $\cdot$ Chronic kidney disease of unknown origin · Human nutrition}

\begin{abstract}
Background: In agricultural communities in Central and South America, Egypt, India, and Sri Lanka, an unexplained form of chronic kidney disease affects agricultural workers. Termed chronic kidney disease of unknown origin (CKDu), it disproportionately affects young men in their $30 \mathrm{~s}-40$ s and is unrelated to the traditional risk factors of diabetes, hypertension, and obesity [1-3]. Recent investigations suggest that agricultural work in the USA carries similar risks, as reduced kidney function has been found among those working in US agriculture [4-5]. However, researchers are yet to determine the etiology of the disease [6-8]. Central to the hypotheses of CKDu is the reduced blood flow to the kidneys due to inadequate hydration during periods of intense physical labor. Objectives: The primary aim of the current investigation was to identify if a relationship between hydration and kidney function exists among the general population by using the data from the National Health and Nutrition Ex-
\end{abstract}

amination Survey (NHANES). We hypothesize that reduced hydration will be associated with reduced kidney function. Methods: Data were retrieved from the NHANES dataset from 3 sample years 2005/2006, 2007/2008, and 2011/2012. Data were merged across all 3 periods with survey weights adjusted for combining across multiple years. Participants were excluded if they had missing data for hydration or kidney function, or if they were $<19$ year. Kidney function was categorized low risk, moderate risk, or high risk for impaired function based on estimated glomerular filtration rate and albumin creatinine ratio according to the National Kidney Foundation [9]. Hydration was classified based on total water intake (TWI) extracted from plain water intake and water from food. Participants were labeled as high if they met or exceeded sex-specific water recommendations, 3.7 and 2.7 $\mathrm{L} /$ day for men and women, respectively; otherwise they were labeled as low. A survey-weighted proportional odds logistic regression model was fitted to assess the association between water intake and kidney function, while controlling for other demographic, socio-economic, behavioral, and socio-economic risk factors [10-12]. Results: Of the 13,056 participants initially sampled, 10,651 participants are included in the analysis after cleaning and including survey weights. $9,125(85.67 \%)$ of participants were in the low-risk group, karger@karger.com www.karger.com/anm

Karger $\stackrel{\text { ' }}{5}$

GOPEN ACCESS
(C) 2022 The Author(s)

Published by S. Karger AG, Basel

This article is licensed under the Creative Commons Attribution 4.0 International License (CC BY) (http://www.karger.com/Services/ OpenAccessLicense). Usage, derivative works and distribution are permitted provided that proper credit is given to the author and the original publisher.
Correspondence to:

David Lartey, david.lartey@montana.edu 
$1,128(10.59 \%)$ were classified as medium-risk, while the remaining 398 (3.74\%) were high risk (Fig. 1). Adjusting for survey weights, results suggest that the estimated rate of highrisk kidney function was $5 \%$ more for low water drinkers compared to high water drinkers (Fig. 2). There is strong evidence of a difference in CKD risk categories based on TWI $\left(X^{2}(1)=13.1, p\right.$ value $\left.<0.0001\right)$ from a survey-weighted proportional odds logistic regression model, but only moderate evidence of a difference when controlled for sodium/potas-

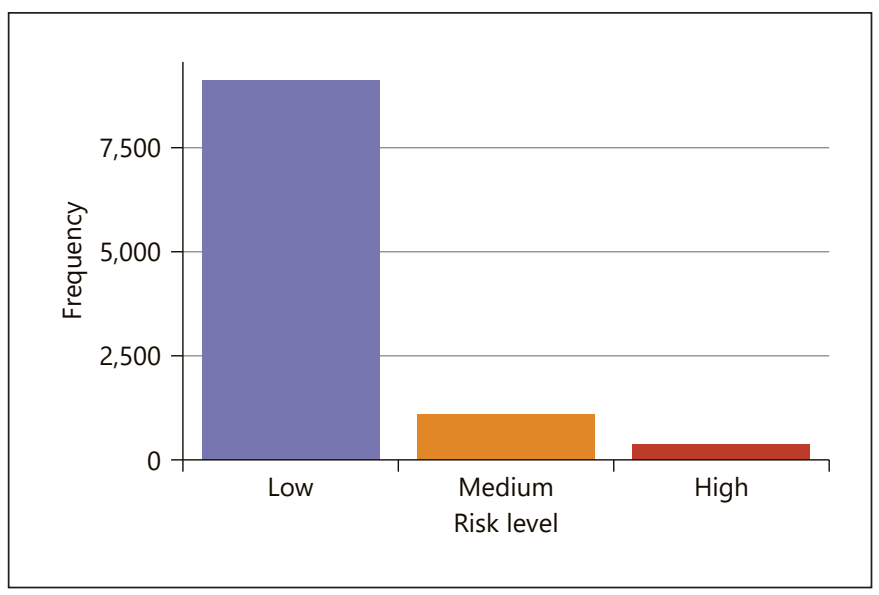

Fig. 1. Distribution of kidney function risk by study participants using survey weights.

\section{Statement of Ethics}

This article does not contain any studies involving animals performed by any of the authors. This article does not contain any studies involving human participants performed by any of the authors. Study approval statement: No review by the Institutional Review Board was required because the analysis of de-identified, publicly available data does not constitute human subjects research as defined at 45 CFR 46.102 and that it does not require IRB review. Consent to participate statement: Health information collected in the NHANES is kept in strictest confidence. During the informed consent process, survey participants are assured that data collected will be used only for stated purposes and will not be disclosed or released to others without the consent of the individual or the establishment in accordance with section 308(d) of the Public Health Service Act (42 U.S.C. $242 \mathrm{~m}$ ). sium ratio, education, age, gender, ethnicity, income, $\mathrm{BMI}$, blood pressure, diabetes, smoking, and alcohol consumption $\left(x^{2}(1)=3.3, p\right.$ value $\left.=0.067\right)$. Conclusions: Not meeting recommended daily TWI was associated increased presentation of high-risk kidney function. Even though the NHANES data are not focused on areas where chronic kidney disease is prevalent, results from this are an indication that hydration does play a role in kidney function.

(C) 2022 The Author(s)

Published by S. Karger AG, Basel

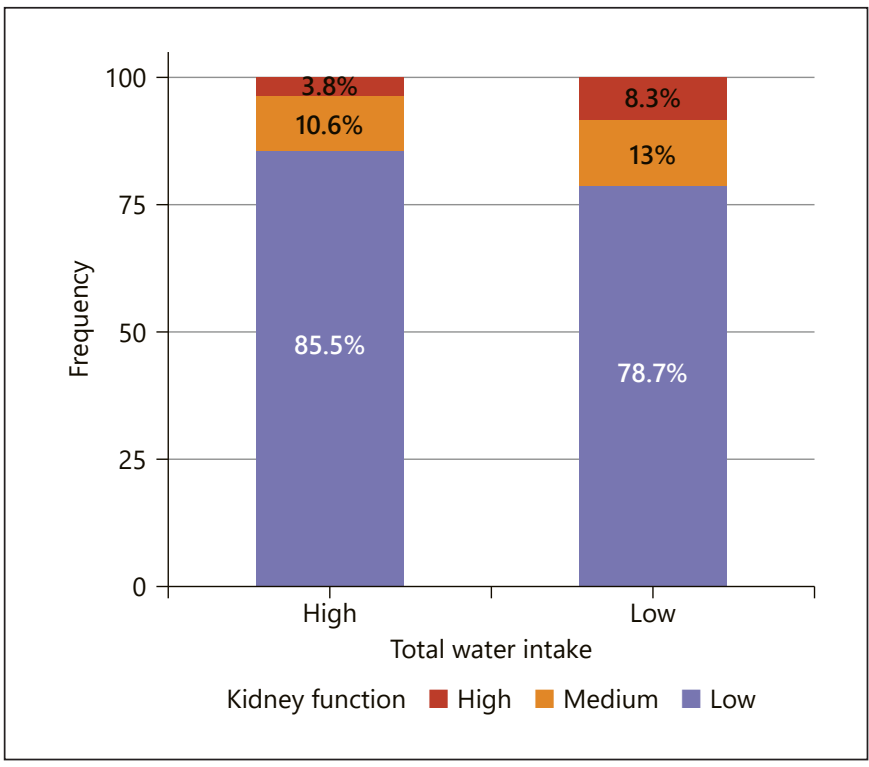

Fig. 2. Association between TWI and kidney function after adjusting for survey weights. TWI, total water intake.

\section{Conflict of Interest Statement}

Author Evan C. Johnson has previously received grant funding from Danone Research. All other authors have no conflicts of interest to declare.

\section{Funding Sources}

Research reported in this publication was supported by the $\mathrm{Na}$ tional Institute of General Medical Sciences of the National Institutes of Health under Award Number P20GM103432. The content is solely the responsibility of the authors and does not necessarily represent the official views of the National Institutes of Health. 


\section{Author Contributions}

David Lartey contributed to acquisition, analysis, and interpretation of data; drafting the work; and final approval of the version to be published. Mark Greenwood and Greta Linse contributed to acquisition, analysis, and interpretation of data; critical revision of the work; and final approval of the version to be published. Sally Moyce, Evan C. Johnson, and Cynthia Curl contributed to the design of the work and interpretation of data; critical revision of the work; and final approval of the version to be published. - Meredith Spivak contributed to acquisition and interpretation of data; critical revision of the work; final approval of the version to be published.

\section{Data Availability Statement}

The data that support findings of this study are publicly available. Reasonable requests for coded and weighted data should be addressed to the corresponding author, D.L.

\section{References}

1 Wesseling C, Crowe J, Hogstedt C, Jakobsson $\mathrm{K}$, Lucas R, Wegman DH. The epidemic of chronic kidney disease of unknown etiology in Mesoamerica: a call for interdisciplinary research and action. Am J Public Health. 2013;103(11):1927-30.

2 Correa-Rotter R, Wesseling C, Johnson RJ. CKD of unknown origin in Central America: the case for a Mesoamerican nephropathy. Am J Kidney Dis. 2014;63(3):506-20.

3 Johnson RJ, Wesseling C, Newman LS, Chronic kidney disease of unknown cause in agricultural communities. N Engl J Med. 2019;381(19):689-52.

4 Moyce S, Joseph J, Tancredi D, Mitchell D, Schenker M. Cumulative incidence of acute kidney injury in California's agricultural workers. J Occup Environ Med. 2016;58(4): 391-7.
5 Mix J, Elon L, Vi Thien Mac V, Flocks J, Economos E, Tovar-Aguilar AJ, et al. Hydration status, kidney function, and kidney injury in Florida agricultural workers. J Occup Environ Med. 2018;60(5):e253-e260.

6 García-Trabanino R, Jarquín E, Wesseling C, Johnson RJ, González-Quiroz M, Weiss I, et al. Heat stress, dehydration, and kidney function in sugarcane cutters in El Salvador: a cross-shift study of workers at risk of Mesoamerican nephropathy. Environ Res. 2015 Oct 1;142:746-55.

7 Bandara JM, Wijewardena HV, Liyanege J, Upul MA, Bandara JM. Chronic renal failure in Sri Lanka caused by elevated dietary cadmium: trojan horse of the green revolution. Toxicol Lett. 2010;198(1):33-9.
8 Elinder CG, Wernerson A, Wijkstrom J. Mesoamerican Nephropathy (MeN). A "newchronic kidney disease related to occupational heat exposure with repeated deprivation of salts and water. Int J Nephrol Kidney Fail. 2015;1(2). Available from: https://www.sciforschenonline.org/journals/nephrologykidney/article-data/IJNKF-1 - 109 / IJNKF-1-109.pdf. Accessed 2015 Nov 16.

9 National Kidney Foundation. Estimated glomerular filtration rate (eGFR). National Kidney Foundation; 2020. Available from: https: //www.kidney.org/atoz/content/gfr.

10 Lumley T. Survey: analysis of complex survey samples; 2020. R package version 4.0. 2021.

11 Lumley T. Analysis of complex survey samples. J Stat Soft. 2004 Apr 15;9(8):1-9.

12 Lumley T. Complex surveys: a guide to analysis using R. John Wiley \& Sons; 2011 Sep 20. 